\title{
Evaluation of phase and thermoelectric properties of thin film $\mathrm{SrSi}_{2}$
}

\author{
Kodai AOYAMA ${ }^{1}$, Takao SHIMIZU ${ }^{1}$, Hideto KURAMOCHI ${ }^{2}$, Masami MESUDA ${ }^{2}$, Ryo AKIIKE ${ }^{2}$, \\ Yoshisato KIMURA ${ }^{1}$ and Hiroshi FUNAKUBO ${ }^{1, \dagger}$ \\ ${ }^{1}$ School of Materials and Chemical Technology, Tokyo Institute of Technology, \\ 4259 Nagatsuda, Midori-ku, Yokohama 226-8502, Japan \\ ${ }^{2}$ Tosoh Corporation, Ayase, Kanagawa 252-1123, Japan
}

\begin{abstract}
We firstly prepared $\mathrm{SrSi}_{2}$ thin films on insulating substrates and measured their thermoelectric properties. Thin films of $\mathrm{Sr}-\mathrm{Si}$ system were deposited on (0001) $\mathrm{Al}_{2} \mathrm{O}_{3}$ substrates by radio frequency magnetron sputtering method at various deposition temperatures and under various total deposition pressure. Constituent phases primary depend on the deposition temperature. The films deposited below $600^{\circ} \mathrm{C}$ consisted of amorphous or the metastable $\mathrm{CaSi}_{2}$ structure phase. $\mathrm{CaSi}_{2}$ structure phase was obtained at $600^{\circ} \mathrm{C}$ irrespective of the pressure and finally stable $\alpha$ - $\mathrm{SrSi}_{2}\left(\alpha\right.$-phase) above $700^{\circ} \mathrm{C}$. The films with $\mathrm{CaSi}_{2}$ structure phase had low power factor below $10 \mu \mathrm{W} \mathrm{m} \mathrm{m}^{-1} \mathrm{~K}^{-2}$ for the temperature range between 100 and $400^{\circ} \mathrm{C}$. On the other hand, the film with $\alpha$-phase showed $p$-type conduction and good thermoelectric power factor beyond $700 \mu \mathrm{W} \mathrm{m}^{-1} \mathrm{~K}^{-2}$ at room temperature. This value is larger than the reported value of (111) one-axis-oriented $\mathrm{Mg}_{2} \mathrm{Si}$ films prepared by the same deposition process, maximum $130 \mu \mathrm{W} \mathrm{m}{ }^{-1} \mathrm{~K}^{-2}$ at $300^{\circ} \mathrm{C}$. The present result shows that $\alpha$-phase is one of the promising candidates as thermoelectric materials.

(C2019 The Ceramic Society of Japan. All rights reserved.
\end{abstract}

Key-words : $\mathrm{SrSi}_{2}$ thin films, Crystal structure, Thermoelectric

[Received January 8, 2019; Accepted February 4, 2019]

\section{Introduction}

Recently, thermoelectric materials have been widely investigated. ${ }^{1)-6)}$ Thermoelectric materials are capable of converting waste heat into usage electricity. ${ }^{7)}$ The technology of energy conversions from waste heat into electrical energy is very important for reduction of generating energy from fossil fuels. ${ }^{8)}$ A dimensionless figure of merit $Z T\left(S^{2} \rho^{-1} \kappa^{-1} T\right)$ is widely used for indicating the thermoelectric performance of the material. The term concerning electronic properties of figure of merit is called power factor $\left(S^{2} \rho^{-1}\right)$. It is very important to discover the novel materials with high power factor because $\kappa$ has been demonstrated to be lowered by the introduction of nanostructure etc. ${ }^{9)}$ without changing material such as heavy element substitution. ${ }^{10)}$

Thermoelectric thin films are also potential cooling applications. ${ }^{11)}$ For cooling application, thickness of thermoelectric materials should be as small as possible, according to the formula of the maximum cooling density. ${ }^{12)}$ However, when materials are made into a thin film, the electrical resistivity often increases ${ }^{13)}$ and the perform-

Corresponding author: H. Funakubo; E-mail: funakubo.h. aa@m.titech.ac.jp

* Preface for this article: Dol http://doi.org/10.2109/jcersj2. 127.P6-1 ance is degraded from that of the bulk. ${ }^{14)}$ Furthermore, it is not always possible to produce the same materials as bulk because the thin film fabrication process is a nonequilibrium process. ${ }^{15), 16)}$ Therefore, it is necessary to study thin film with good thermoelectric performance, as well as bulk material.

In recent years, silicide-based materials attract attention as promising candidate for thermoelectric materials. ${ }^{17)}$ Silicide compounds have advantages such as low environmental load, abundant constituent elements in the earth's crust, high compatibility with the Si process. The famous thermoelectric silicides are $\mathrm{Mg}_{2} \mathrm{Si}$ and $\mathrm{Mn}-\mathrm{Si}$ systems ${ }^{14), 18)-20)}$ because of good thermoelectric property. They have been widely investigated with not only bulk form but also thin film form. The $\alpha-\mathrm{SrSi}_{2}{ }^{21)-23)}$ (described as $\alpha$-phase) is also a promising candidate as a thermoelectric material because it is environmentally friendly and a good thermoelectric power factor near the room temperature. ${ }^{24)-26)}$ Furthermore, $\mathrm{SrSi}_{2}$ has other phases showing interesting electrical properties. Although this $\alpha$-phase is the most stable phase, several polymorphs are known. For example, $\beta$-phase ${ }^{23), 27)}$ has been recognized as high pressure and high temperature phase, which is produced by compression in a belt-type apparatus at a pressure of $4 \mathrm{GPa}$ with heating at $1000-1500^{\circ} \mathrm{C}$ and decompression after quenching to room temperature. ${ }^{28)}$ This phase is known as a superconductor. ${ }^{29)} \mathrm{SrSi}_{2}$ thin films prepared at $500^{\circ} \mathrm{C}$ 

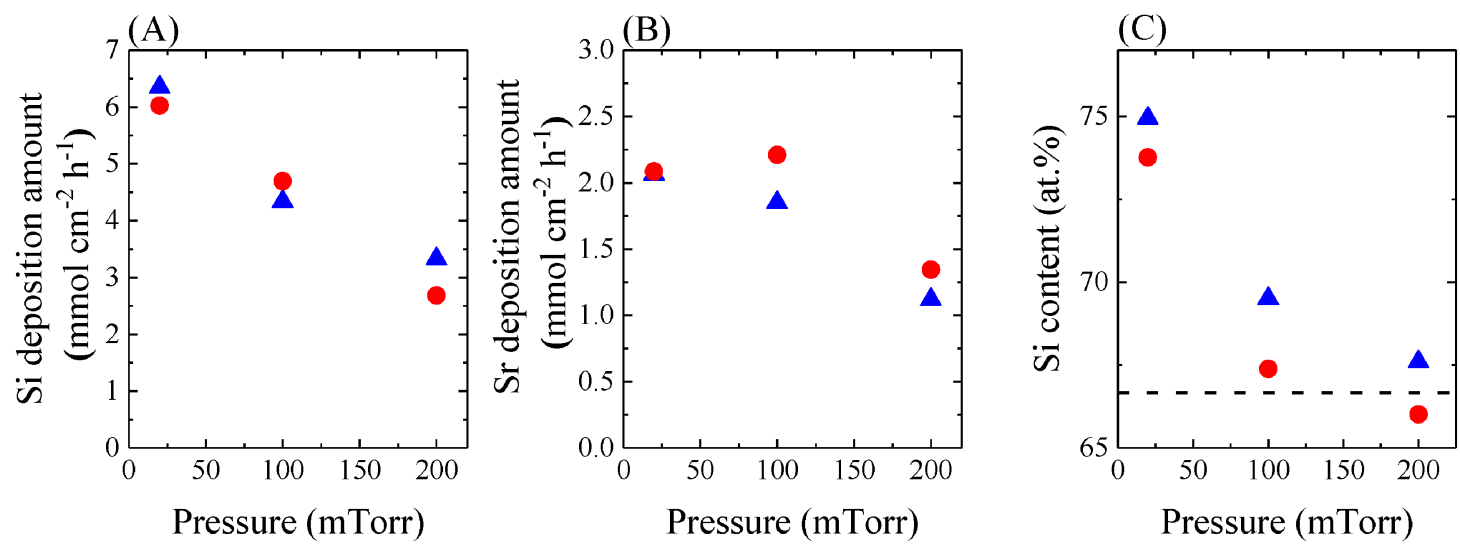

Fig. 1. Deposition pressure dependences of (A) Si deposition amount, (B) Sr deposition amount, and (C) Si content of the films deposited at 700 or $600^{\circ} \mathrm{C}$. Circles indicate $700^{\circ} \mathrm{C}$ and triangles indicate $600^{\circ} \mathrm{C}$. A dashed line in (C) indicates stoichiometric Si content of $\mathrm{SrSi}_{2}$.

by a Molecular Beam Epitaxy (MBE) method is reported to have the phase with $\mathrm{CaSi}_{2}$ structure ${ }^{30), 31}$ (hereinafter described as $\mathrm{CaSi}_{2}$ structure phase), which has not been reported in bulk, and showed very low electrical resistivity on the order of $10^{-5} \Omega \mathrm{cm}^{31)}$ This structure has "silicene layers", which is the analogue of graphene consisting of $\mathrm{Si}$ atoms, in its unit cell, attracting much attentions. ${ }^{30)}$ Thus, it is essential to investigate the conditions comprehensively to synthesis $\mathrm{SrSi}_{2}$ thin films with desired phases.

In this study, $\mathrm{SrSi}_{2}$ thin films were deposited on (001) $\mathrm{Al}_{2} \mathrm{O}_{3}$ substrates by radio frequency (RF) magnetron sputtering method at various deposition temperature and sputter pressure. The deposition at low temperature below $600^{\circ} \mathrm{C}$ resulted in $\mathrm{CaSi}_{2}$ structure phase, while the deposition at high temperature provided $\alpha$-phase. The temperature-dependent electrical resistivity and Seebeck coefficient were measured, leading to resultant power factor of $700 \mu \mathrm{W} \mathrm{m}{ }^{-1} \mathrm{~K}^{-2}$ at $100^{\circ} \mathrm{C}$.

\section{Experimental}

$\mathrm{SrSi}_{2}$ films with $2 \mu \mathrm{m}$ in thickness were prepared on (001) $\mathrm{Al}_{2} \mathrm{O}_{3}$ substrates by $\mathrm{RF}$ magnetron sputtering method under $\mathrm{Ar}$ with $5 \% \mathrm{H}_{2}$. A sintered body of $\mathrm{SrSi}_{2}$ with 1.3 inch in diameter was used as a sputtering target. The deposition temperature was varied from 200 to $700^{\circ} \mathrm{C}$, while the deposition total pressure was changed from 20 to 200 mTorr. The input power for sputtering and target-substrate distance were maintained at $20 \mathrm{~W}$ and $60 \mathrm{~mm}$, respectively.

$\mathrm{The} \mathrm{Si} /(\mathrm{Sr}+\mathrm{Si})$ ratio, $\mathrm{Si}$ content, of the deposited film was measured by the X-ray fluorescence spectrometry (XRF) (PANalytical PW4400). Constituent phase of the films was characterized by X-ray diffraction (XRD) method (Bruker AXS D8 discover). XRD 2 $\theta-\theta$ scans were repeated by changing the sample inclination angle $(\psi)$ under the sample rotation condition. Integrated $2 \theta-\theta$ scans was obtained by integrated along $\psi$ direction. ${ }^{32}$

The temperature dependences of the electrical resistivity and Seebeck coefficient were measured from room temperature to $400^{\circ} \mathrm{C}$ in $\mathrm{He}$ atmosphere and reduced pressure (ULVAC ZEM-3).

\section{Results and discussion}

\subsection{Film composition and crystal structure}

Figure 1 shows the results obtained using XRF. Figures 1(A) and 1(B) show the deposition amount of $\mathrm{Si}$ and $\mathrm{Sr}$ respectively, revealing that the higher deposition pressure decreases deposition amount. This trend is more prominent, especially for Si. Therefore, the Si content of the films decreased with increasing the pressure. The reason for this is considered that Si is more easily scattered because of its small atomic weight. From this result, it was possible to adjust the composition by controlling the deposition pressure. Regarding to deposition temperature, the films deposited at $600^{\circ} \mathrm{C}$ (hereinafter described as $600^{\circ} \mathrm{C}$ films) had larger $\mathrm{Si}$ content in the films than the films deposited at $700^{\circ} \mathrm{C}$ (hereinafter described as $700^{\circ} \mathrm{C}$ films).

Figures 2(A) and 2(B) show the integrated XRD results for the $600^{\circ} \mathrm{C}$ films and $700^{\circ} \mathrm{C}$ films deposited under various deposition pressure. These XRD patterns indicate that the majority phase was $\mathrm{CaSi}_{2}$ structure phase for all $600^{\circ} \mathrm{C}$ films regardless of the deposition pressure, as confirmed by 100,101 , and 102 diffraction peaks. It must be noted that a peak at around $28^{\circ}$ is $\mathrm{Si} 111$. This Si peak intensity increased with decreasing deposition pressure. This indicates that the volume fraction of Si secondary phase increased with decreasing deposition pressure. The presence of Si secondary phase is due to Si-excess composition against $\mathrm{SrSi}_{2}$ that was confirmed by XRF measurement as shown in Fig. 1 . In contrast to $600^{\circ} \mathrm{C}$ films, $\alpha$-phase was the majority phase for all deposition pressures at $700^{\circ} \mathrm{C}$. This can be confirmed by the $111,210,211$, and 220 peaks of $\alpha$-phase. The Si 111 peak was also observed for the films deposited at $700^{\circ} \mathrm{C}$. At 100 and $200 \mathrm{mTorr}$, the films with stoichiometric ratio were obtained.

Figure 3 displays the constituent phase as a function of deposition temperature and $\mathrm{Si}$ content of the film, showing the growth of $\alpha$-phase at $700^{\circ} \mathrm{C}$ and $\mathrm{CaSi}_{2}$ structure phase at $600^{\circ} \mathrm{C}$ as confirmed in Fig. 2 The constituent phase below $600^{\circ} \mathrm{C}$, show $\mathrm{CaSi}_{2}$ structure phase or amorphous (no detectable peak on XRD pattern). Boundary between 

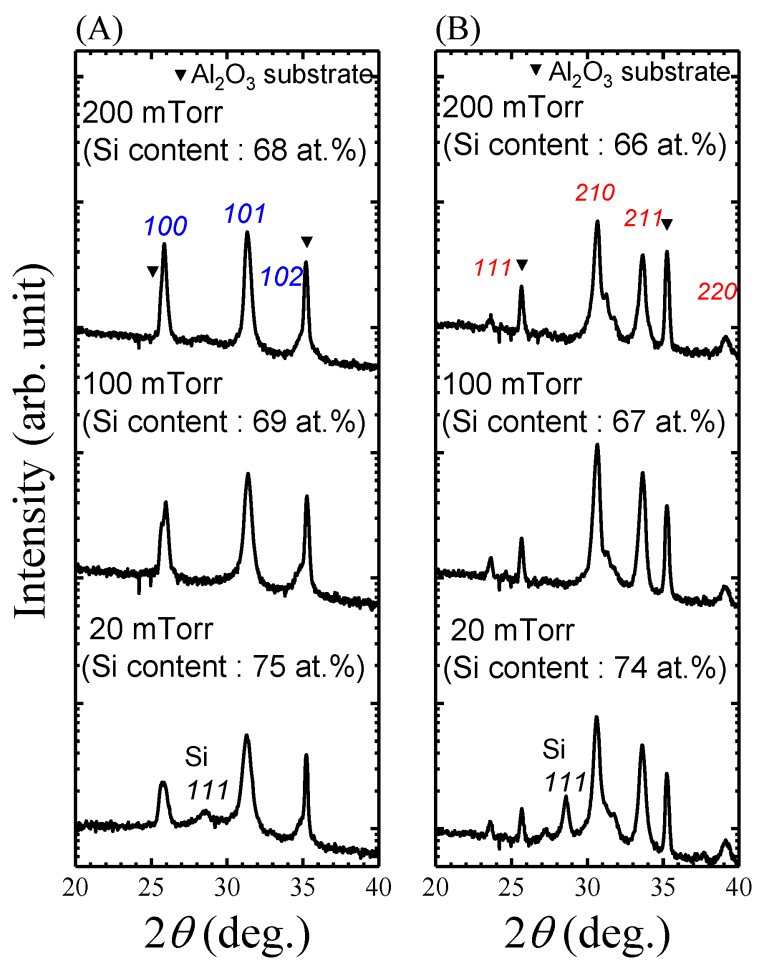

Fig. 2. Deposition pressure dependences of XRD profiles of the films deposited at (A) $600^{\circ} \mathrm{C}$ and (B) $700^{\circ} \mathrm{C}$.

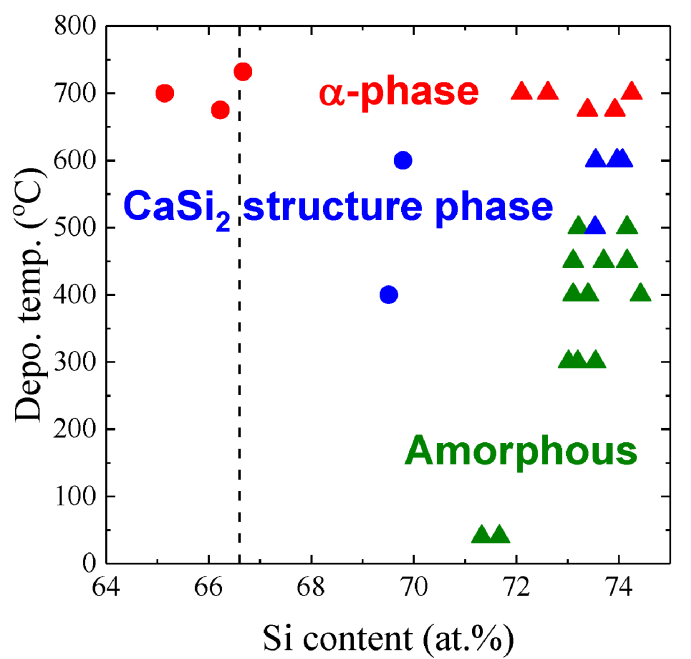

Fig. 3. Constituent phase depended on deposition temperature and $\mathrm{Si}$ content. A dashed line in the graph indicates stoichiometric Si content of $\mathrm{SrSi}_{2}$. Circles indicate the films deposited at $100 \mathrm{mTorr}$ and triangles indicate the films deposited at $20 \mathrm{mTorr}$.

$\mathrm{CaSi}_{2}$ structure phase and amorphous depended on not only deposition temperature but also Si contents of the films. These results differ from the information from the phase diagram, ${ }^{23)}$ but are similar to the film preparation condition especially in temperature reported in the present study. ${ }^{22), 31)}$ In this study, we had grown the both $\alpha$-phase and $\mathrm{CaSi}_{2}$ structure phase, on the other hand, had not the $\beta$-phase probably due to low deposition temperature and pressure. The confirmation of $\mathrm{CaSi}_{2}$ structure phase is consistent with the previous result using $\mathrm{MBE}$ at $500^{\circ} \mathrm{C} .{ }^{31)}$

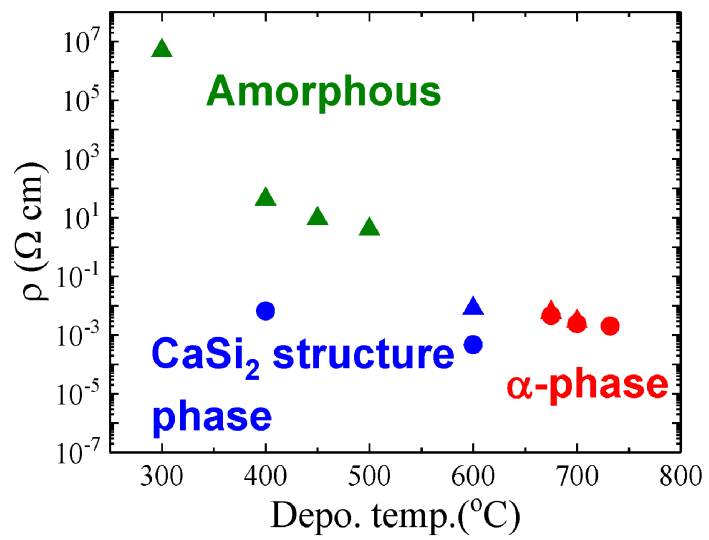

Fig. 4. Deposition temperature dependences of electrical resistivity. Circles indicate the film deposited at $100 \mathrm{mTorr}$ and triangles indicate the film deposited at 20 mTorr.

These results indicate that the relatively lower deposition temperature might lead to the $\mathrm{CaSi}_{2}$ structure phase. It should be mentioned that $\mathrm{CaSi}_{2}$ structure phase have not been observed in bulk because $600^{\circ} \mathrm{C}$ is too low to obtain significant diffusion for fabrication of the bulk.

\subsection{Thermoelectric properties}

Figure 4 summarizes the electric resistivity at room temperature as a function of deposition temperature. The increase in resistivity between deposition temperatures from 200 to $600^{\circ} \mathrm{C}$ might be due to the increase in the size of crystallite, which reduce the carrier scattering at the grain boundary. The high resistivity of $700^{\circ} \mathrm{C}$ films compared to $600^{\circ} \mathrm{C}$ films accords the previous studies. These studies showed the $\alpha$-phase is semimetal, while the $\mathrm{CaSi}_{2}$ structure phase exhibits normal metallic characteristics. Thus, the change in the formed phase would provide the decrease in the resistivity with increasing deposition temperature.

Figure 5(A) shows the temperature dependence of electrical resistivity of $\mathrm{CaSi}_{2}$ structure phase and $\alpha$-phase. The films consisting of $\mathrm{CaSi}_{2}$ structure phase showed lower electrical resistivity than that with $\alpha$-phase. In addition, the resistivity of the present film of $\mathrm{CaSi}_{2}$ structure phase is about 100 times larger than that of epitaxial films in previous study. ${ }^{31)}$ This difference is probably due to the difference in crystallinities; the present film is polycrystalline one, whereas the reported film was epitaxial one. The films consisting of $\alpha$-phase showed similar trend to the reported value for polycrystalline bulk consist of $\alpha$-phase by Imai et al. ${ }^{26)}$ but their absolute value is slightly larger. When a film is prepared by sputtering, films consist of the columnar grains. There might be a lot of grain boundaries along the in-plane direction due to the small grain size on several tens to hundreds $\mathrm{nm}$. Since electrical resistivity was measured along the in-plane direction, the carrier tend to be scattered at the grain boundary, leading to the higher resistivity than that of bulk

Figure 5(B) shows temperature dependence of Seebeck coefficients of $\mathrm{CaSi}_{2}$ structure phase and $\alpha$-phase. The 


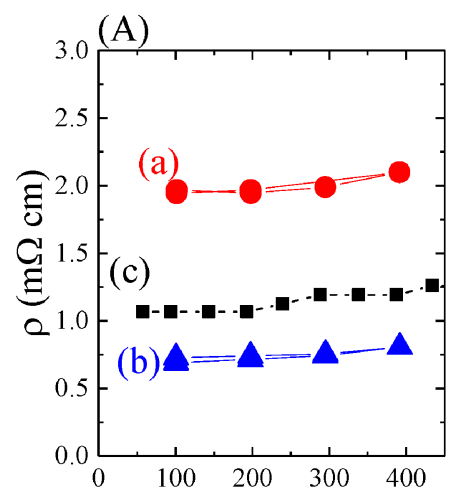

Temperature $\left({ }^{\circ} \mathrm{C}\right)$
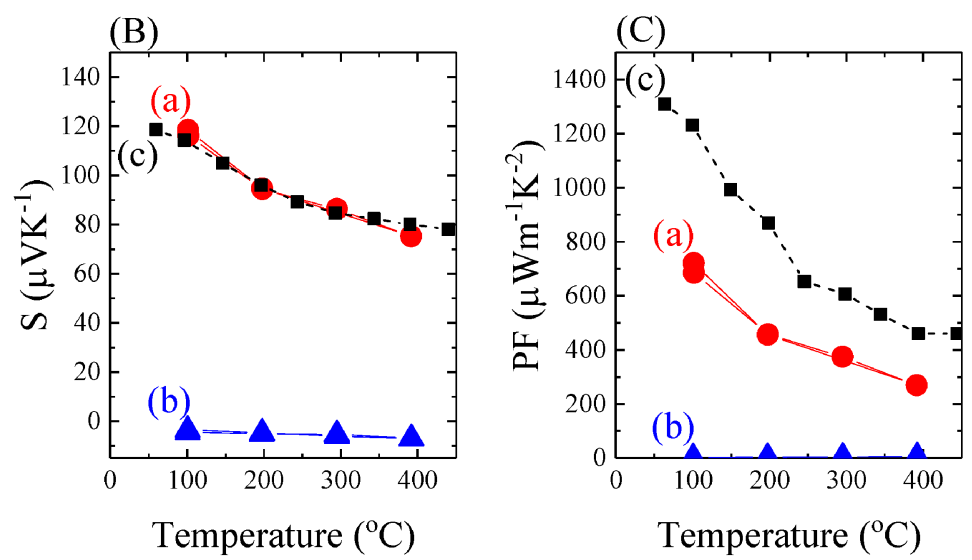

Fig. 5. Pressure dependences of (A) electrical resistivity, (B) Seebeck Coefficient, and (C) power factor. (a) Circles indicate $700^{\circ} \mathrm{C}$ film, (b) triangles indicate $600^{\circ} \mathrm{C}$ film (c) squares indicate the data reported for stoichiometric $\mathrm{Si}$ content of $\mathrm{SrSi}_{2}{ }^{24)}$

Seebeck coefficients of $\mathrm{CaSi}_{2}$ structure phase is about -6 $\mu \mathrm{V} \mathrm{K}^{-1}$ over the entire temperature range. This small value shows the metallic characteristics. On the other hand, relatively large value of 120 and $80 \mu \mathrm{V} \mathrm{K}^{-1}$ at 27 and $300^{\circ} \mathrm{C}$, respectively were observed for the film consist of $\alpha$-phase. This large value is also in good agreement with the reported one for the bulk polycrystalline sample. ${ }^{24)}$

Figure 5(C) shows temperature dependence of power factor of $\mathrm{CaSi}_{2}$ structure phase and $\alpha$-phase. The power factor of $\mathrm{CaSi}_{2}$ phase was less than $10 \mu \mathrm{W} \mathrm{m}{ }^{-1} \mathrm{~K}^{-2}$ for all temperature range due to small Seebeck coefficients. On the other hand, $\alpha$-phase had $700 \mu \mathrm{W} \mathrm{m}{ }^{-1} \mathrm{~K}^{-2}$ at $100^{\circ} \mathrm{C}$. This value is smaller than that of $\alpha-\mathrm{SrSi}_{2}$ bulk, but larger than those of our previously reported $\mathrm{Mg}_{2} \mathrm{Si}$ and $\mathrm{Ca}_{3} \mathrm{Si}_{5}$ films deposited by the same process. ${ }^{14), 33)}$ The famous thermoelectric materials of $\mathrm{Bi}_{2} \mathrm{Te}_{3}$ showed over $1000 \mu \mathrm{W} \mathrm{m}{ }^{-1} \mathrm{~K}^{-2}$ at $27^{\circ} \mathrm{C}$ in a film form, ${ }^{34)}$ which is much lower than that of bulk. In contrast, $\alpha$-phase thin film showed less degraded properties, compared to the bulk. Therefore $\alpha$-phase is one of the promising candidates for the thermoelectric application with the materials with film form.

\section{Conclusions}

We investigated the formation condition of $\mathrm{SrSi}_{2}$ films and measured thermoelectric properties of the films. It was found that the crystal structure of the $\mathrm{SrSi}_{2}$ films varies depending on the deposition temperature and that $\mathrm{Si}$ content can be controlled by the deposition pressure. For the deposition at $600^{\circ} \mathrm{C}$, films of $\mathrm{CaSi}_{2}$ structure phase were formed. Polycrystalline $\mathrm{CaSi}_{2}$ structure phase has low electric resistivity regardless of the temperature range and metallic behavior. By the $700^{\circ} \mathrm{C}$ deposition, films of $\alpha$-phase were formed. It showed the power factor of 700 $\mu \mathrm{W} \mathrm{m}{ }^{-1} \mathrm{~K}^{-2}$ at $100^{\circ} \mathrm{C}$ and might show larger value at room temperature. This power factor is larger than other silicide films like $\mathrm{Mg}_{2} \mathrm{Si}$ and $\mathrm{Ca}_{5} \mathrm{Si}_{3}$ prepared by the same method. Moreover, the less degraded properties from the bulk of $\alpha$-phase films enables itself to be one of promising thermoelectric materials for thin film application at room temperature.

\section{References}

1) K. Fujimoto, M. Gibu, Y. Yamaguchi and A. Aimi, J. Ceram. Soc. Jpn., 125, 308-312 (2017).

2) S. Narushima, R. Shimonishi, M. Hagiwara and $S$. Fujihara, J. Ceram. Soc. Jpn., 126, 286-291 (2018).

3) H. Takizawa, J. Ceram. Soc. Jpn., 126, 424-433 (2018).

4) Y. Tsujimoto, J. Ceram. Soc. Jpn., 126, 609-613 (2018).

5) B. Feng, G. Li, Z. Pan, X. Hu, P. Liu, Y. Li, Z. He and X. Fan, J. Ceram. Soc. Jpn., 126, 699-705 (2018).

6) J. Zhai, H. Wang, W. Su, T. Wang, X. Wang, T. Chen and C. Wang, J. Ceram. Soc. Jpn., 127, 22-27 (2019).

7) T. M. Tritt, Science, 283, 804-805 (1999).

8) T. M. Tritt and M. A. Subramanian, MRS Bull., 31, 188198 (2006).

9) Z. G. Chen, G. Hana, L. Yanga, L. Cheng and J. Zou, Prog. Nat. Sci. Mater. Int., 22, 535-549 (2012).

10) F. J. DiSalvo, Science, 285, 703-706 (1999).

11) I. Chowdhury, R. Prasher, K. Lofgreen, G. Chrysler, S. Narasimhan, R. Mahajan, D. Koester, R. Alley and R. Venkatasubramanian, Nat. Nanotechnol., 4, 235-238 (2009).

12) H. Böttner, J. Nurnus and A. Schubert, in "Thermoelectrics Handbook: Macro to Nano", Ed. by D. M. Rowe (2005) pp. 46.1-46.16.

13) T. H. Gilani and D. Rabchuk, Can. J. Phys., 96, 272274 (2018).

14) S. Ogawa, A. Katagiri, T. Shimizu, M. Matsushima, K. Akiyama, Y. Kimura, H. Uchida and H. Funakubo, J. Electron. Mater., 43, 2269-2273 (2014).

15) S. Müller, P. Bayer, C. Reischl, K. Heinz, B. Feldmann, H. Zillgen and M. Wuttig, Phys. Rev. Lett., 74, 765-768 (1995).

16) P. Hemenger and H. Weik, Acta Crystallogr., 19, 690691 (1965).

17) A. T. Burkov, Phys. Status Solidi Appl. Mater. Sci., 215, 1-19 (2018).

18) G. Jiang, J. He, T. Zhu, C. Fu, X. Liu, L. Hu and X. Zhao, Adv. Funct. Mater., 24, 3776-3781 (2014).

19) Q. R. Hou, Z. M. Wang and Y. J. He, Appl. Phys. A-Mater, 80, 1807-1811 (2005).

20) T. Itoh and M. Yamada, J. Electron. Mater., 38, 925929 (2009). 
21) G. E. Pringle, Acta Crystallogr. B, 28, 2326-2328 (1972).

22) D. P. Norton, C. Park, Y. E. Lee and J. D. Budai, J. Vac. Sci. Technol. B, 20, 257-262 (2002).

23) A. Palenzona and M. Pani, J. Alloy. Compd., 384, 227230 (2004).

24) K. Hashimoto, K. Kurosaki, Y. Imamura, H. Muta and S. Yamanaka, J. Appl. Phys., 102, 063703 (2007).

25) Y. Kuo, B. Ramachandran and C. Lue, Front Chem., 2, 1-14 (2014).

26) M. Imai, T. Naka, T. Furubayashi, H. Abe, T. Nakama and K. Yagasaki, Appl. Phys. Lett., 86, 1-3 (2005).

27) J. Evers, G. Oehlinger and A. Weiss, J. Solid State Chem., 20, 173-181 (1977).

28) I. Anorganische and C. Der Universittit, J. Solid State Chem., 207, 199-207 (1978).

29) J. Evers, G. Oehlinger and H. R. Ott, J. Less-Common
Met., 69, 389-391 (1980).

30) J. A. Flores-Livas, R. Debord, S. Botti, A. San Miguel, S. Pailhès and M. A. L. Marques, Phys. Rev. B, 84, 1-7 (2011).

31) A. M. Tokmachev, D. V. Averyanov, I. A. Karateev, O. E. Parfenov, A. L. Vasiliev, S. N. Yakunin and V. G. Storchak, Nanoscale, 8, 16229-16235 (2016).

32) K. Saito, T. Oikawa, T. Kurosawa, T. Akai and H. Funakubo, Jpn. J. Appl. Phys., 41, 6730-6734 (2002).

33) M. Uehara, K. Akiyama, T. Shimizu, M. Matsushima, H. Uchida, Y. Kimura and H. Funakubo, J. Electron. Mater., 45, 3121-3126 (2016).

34) C. Schumacher, K. G. Reinsberg, R. Rostek, L. Akinsinde, S. Baessler, S. Zastrow, G. Rampelberg, P. Woias, C. Detavernier, J. A. C. Broekaert, J. Bachmann and K. Nielsch, Adv. Energy Mater., 3, 95-104 (2013). 